\title{
Experimental Study on the Dynamic Performance of a New High-Speed Spindle Supported by Water-Lubricated Hybrid Bearings
}

\author{
Lin $\mathrm{Wang}^{1}$ and Hua $\mathrm{Xu}^{2}$ \\ ${ }^{1}$ School of Mechanical Engineering, Northwestern Polytechnical University, 127 West Youyi Road, Xian 710072, China \\ ${ }^{2}$ Key Laboratory of Education Ministry for Modern Design and Rotor-Bearing System, Xian Jiaotong University, No. 28, \\ Xianning West Road, Xian 710049, China
}

Correspondence should be addressed to Lin Wang; wanglin@nwpu.edu.cn

Received 30 June 2015; Revised 13 October 2015; Accepted 13 October 2015

Academic Editor: Tai Thai

Copyright (C) 2016 L. Wang and H. Xu. This is an open access article distributed under the Creative Commons Attribution License, which permits unrestricted use, distribution, and reproduction in any medium, provided the original work is properly cited.

\begin{abstract}
The dynamic performance of a new high-speed spindle supported by water-lubricated hybrid bearings is experimentally studied on a test rig. The present design allows the speed of the spindle up to 30,000 rpm, with a bearing internal diameter of $40 \mathrm{~mm}$, which makes it possible to simulate many actual machining processes. Some experiments have been presented to study the mechanical and thermal behaviors of the spindle and its supporting hybrid bearings. The maximum temperature rise is less than $15^{\circ} \mathrm{C}$ with a speed of $30,000 \mathrm{rpm}$ and a water supply pressure of $2.5 \mathrm{MPa}$. The spindle radial run-out of the rotational frequency is about $1 \mu \mathrm{m}$. Stability of the spindle system has been improved. The experimental results indicate that water-lubricated hybrid bearings are valuable choices to replace ceramic bearings and air bearings as support for spindles under high-speed, high-precision, and heavy-load machining conditions.
\end{abstract}

\section{Introduction}

High-speed machining has been widely used in the automobile, aeronautic, shipping, and mold industries for its advantage of high efficiency. Increased cutting speeds are needed for milling and grinding processes. High-speed spindles and supporting bearings, as the key components of machining centers, directly affect machining productivity and the surface quality of work-pieces [1].

A basic feature of high-speed spindle design is the strategy for selecting supporting bearings. Ceramic bearings are the most widely used types in high-speed spindles, but these bearings usually fail to serve for an extended period at high rotational speeds and heavy loads. Spindles supported by air bearings can operate at ultrahigh speeds and have a theoretically infinite life span. However, air bearings are not widely used in heavy-load industrial applications because of their low stiffness and instability.

Fluid-film hybrid/hydrostatic spindles have been used in precision machines because of their low wear and friction, low noise, low contamination, and high precision $[2,3]$. However, the temperature rise increases sharply with rotational speed in oil-lubricated hybrid journal bearings. Such increase results in decreased stability and load carrying capability.

One method for overcoming these problems is to use water-lubricated hybrid journal bearings with high load carrying capability, high stiffness, high precision, and low temperature rise. Some studies have been conducted to investigate the performance of water-lubricated high-speed bearings, which are used in gas turbines, rocket engines, and spindles. Nakano et al. [4] applied water-lubricated bearings in a microturbine system prototype. The rotor with water-lubricated tilting pad journal bearings achieved stable rotating conditions at a rated rotational speed of $51,000 \mathrm{rpm}$. The use of water-lubricated bearings contributes to electrical output efficiency by reducing both bearing losses and auxiliary power consumption. Kurtin et al. [5] used a water-lubricated hybrid journal bearing test rig to investigate the feasibility of using hybrid bearings in the main engine of space shuttles. 


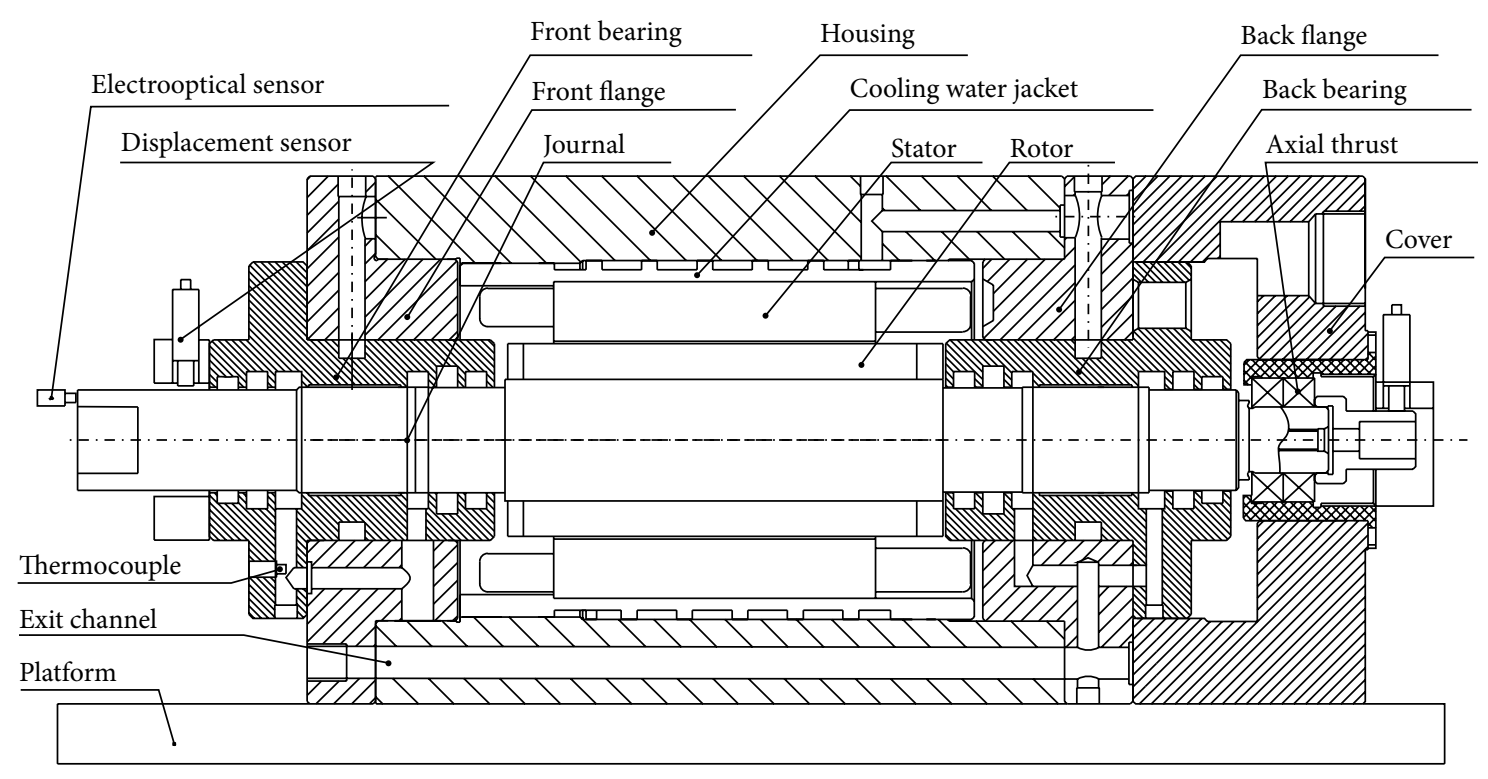

FIGURE 1: Schematic of high-speed spindle system test rig.

The static characteristics of high-speed hybrid bearings used for high-speed spindles have been studied experimentally and theoretically. Yoshimoto et al. [6, 7] investigated the axial load capacity and stability of water-lubricated hydrostatic conical bearings with spiral grooves for highspeed spindles. A rotor supported by such bearings could stably rotate up to $120,000 \mathrm{rpm}$.

However, few studies investigate the dynamic performance of high-speed spindles supported by water-lubricated hybrid journal bearings. Besides, more friction power loss is generated with the increase of the high-speed spindle rotational speed, and then the temperature rise becomes a barrier to the improvement of spindle speed and accuracy [8]. Thus, a water-lubricated high-speed spindle system is developed in this study. The high-speed spindle is supported by two identical water-lubricated hybrid journal bearings with circumferential grooves and stepped recesses $[9,10]$. The test rig is described in detail in the following sections, and valuable data are obtained by imbalance excitation methods.

\section{Experimental Setup}

2.1. Test Rig Configurations. The test rig of the new highspeed spindle is shown in Figure 1. The spindle is driven by a $65 \mathrm{~kW}$ high-speed asynchronous motor. The raw rotor is placed on the journal, and the wound stator is mounted on the inside surface of the housing. Two identical waterlubricated hybrid journal bearings are constrained to the housing through the front and back flanges to support the spindle. Some angular contact ceramic ball bearings are used as the axial thrust to control axial motion. The supporting bearings, along with the flanges and housing, are fixed on the platform using nuts and bolts. The hydropump is switched on before the spindle is activated and is switched off after the spindle stops. The water supply pressure, which is controlled by the hydropump, can change from $0.2 \mathrm{MPa}$ to
3.0 MPa. Radial excitation force can be applied by attaching an imbalance mass onto the inner surface of the spindle end. Water is pumped into the bearing clearance through the filtration units to avoid damage from particles. A reservoir enables the bearings to operate during rotor deceleration if the water supply fails, thus preventing the rotor from seizing on bearing bushings.

2.2. Hybrid Bearing Structure. The hybrid bearing has a diameter of $40 \mathrm{~mm}$ with an L/D ratio of one. The hybrid bearing consists of four stepped recesses and two symmetric circumferential grooves, as shown in Figure 2. The stepped recesses are designed to enhance the dynamic effect. Each stepped recess consists of a deep recess and a shallow recess. The cooling orifices and two circumferential grooves are set symmetrically on both axial lands of the bearing surface to increase the flow rate, reduce the temperature rise, and prevent the lubricant film from rupturing on the bearing surface. Water is fed into the deep recess using an external pressure pump, through the restrictor inlet and cooling inlet, and then through the shallow recesses. Finally, the water exits through the narrow bearing clearance.

2.3. Data Acquisition. The displacement response of the spindle in the horizontal $(x)$ and vertical $(y)$ directions is measured simultaneously with the use of four independent capacitive displacement sensors. The displacement signals are amplified and conditioned using the controllers. An electrooptical sensor is placed at the end of the spindle with a digital counter to provide a phase reference and to record the rotational speed of the spindle. Three thermocouples are used to measure the water temperature at the exits. A computer is used to record the temperature data.

2.4. Experiment Procedure. The experiments were conducted according to the following steps. 


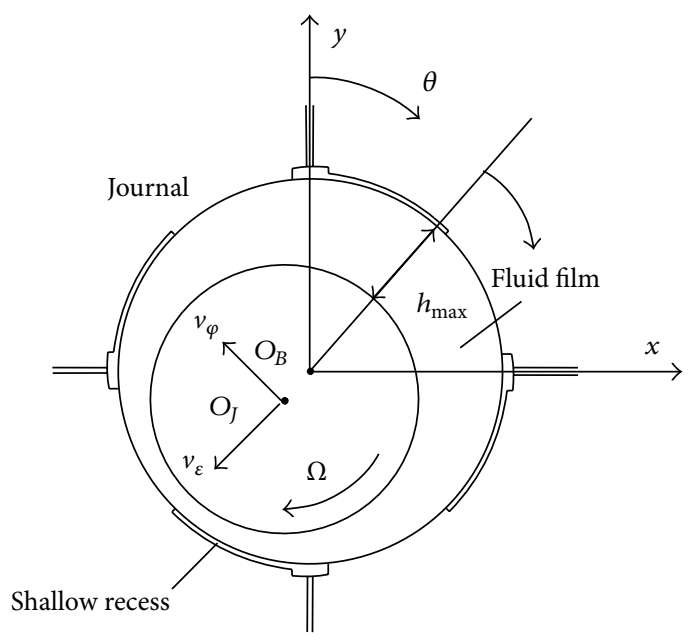

(a)

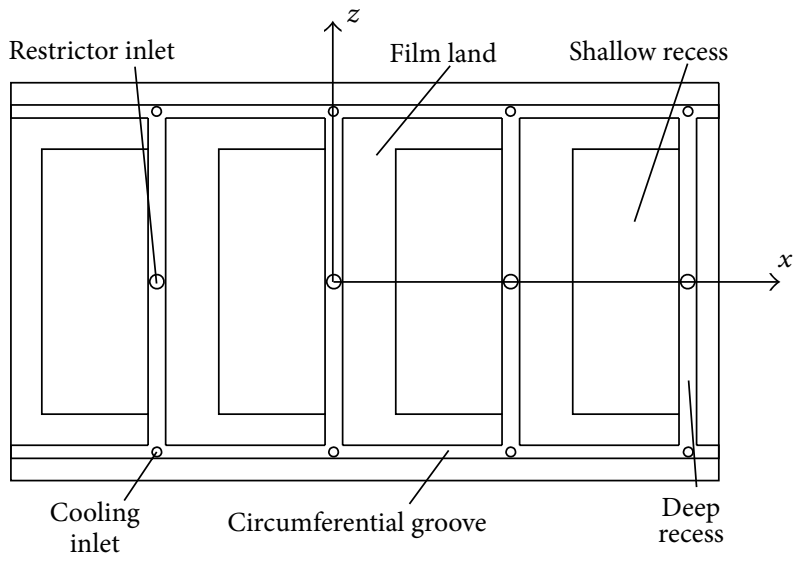

(b)

FIGURE 2: Geometry and coordinate system of the hybrid bearing (a) cross section view and (b) developed view of the bearing surface.

(1) The supply pressure was increased to $2.5 \mathrm{MPa}$. The rotor was activated at 9,000, 12,000, 15,000, 18,000, 21,000 , and $24,000 \mathrm{rpm}$. The corresponding displacement after the vibrations were recorded until the temperature became stable.

(2) The supply pressure was kept constant. Imbalance mass $m 1$ was attached onto the rotor. The first step was then repeated.

(3) The supply pressure was kept constant. Imbalance mass $m 2$ was attached onto the rotor at the same location. The first step was then repeated.

\section{Results and Discussion}

3.1. Temperature Rise, Flow Rate, and Vibration. The temperature rise of water linearly increases with rotational speed as shown in Figure 3. Besides, a comparison has been made, and the results show a good agreement between the experimental and theoretical results. The maximum value is $15^{\circ} \mathrm{C}$ at $30,000 \mathrm{rpm}$. The results present the advantages of the water-lubricated hybrid bearings in lowering temperature rise.

Figure 4 shows the experimental and theoretical flow rate as a function of rotational speed at a supply pressure of $2.5 \mathrm{Mpa}$. The experimental results are in good agreement with the theoretical results. The comparison also validates the numerical model in $[9,10]$.

Figure 5 indicates that vibration amplitude slightly changes with rotational speed. The radial run-out of the rotational frequency is approximately $1 \mu \mathrm{m}$ from $12,000 \mathrm{rpm}$ to $30,000 \mathrm{rpm}$, which is a good evidence for water-lubricated hybrid bearings in improving stability. The vibration peak appears at the half-frequency points, as the asynchronous motor is a four-pole model (right part of Figure 5).

3.2. Orbit. To investigate the effect of speed on dynamic performance, the experiment procedure in Section 2.4 is

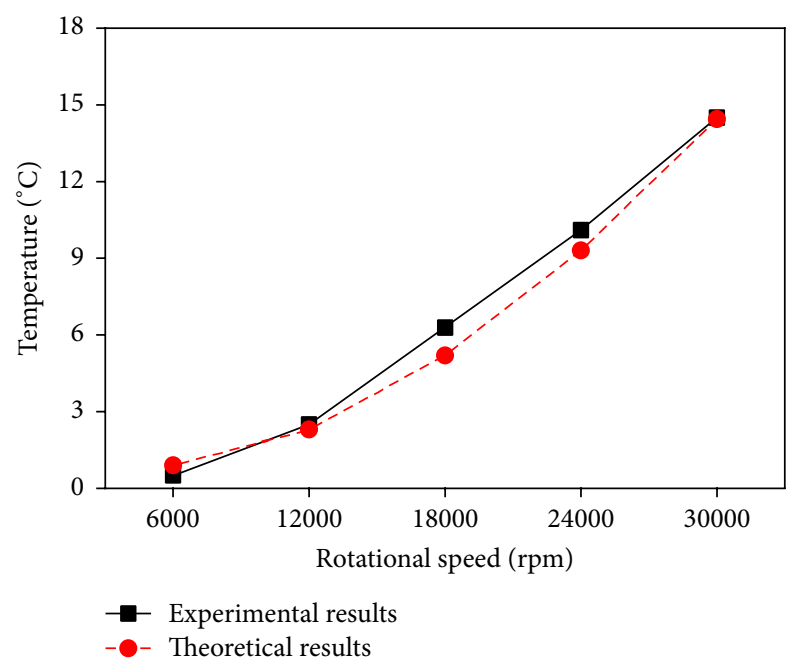

FIGURE 3: Exit temperature rise versus rotational speed at a supply pressure of $2.5 \mathrm{Mpa}$.

followed for six speeds ranging from $9,000 \mathrm{rpm}$ to $24,000 \mathrm{rpm}$ with 3,000 rpm steps.

The orbits near two supporting bearings are recorded at different imbalance forces and rotational speeds. Figures 68 compare the orbits of the front bearing, including those without attached mass and with an attached imbalance mass $m 1=1.7 \mathrm{~g}$ and $m 2=3.0 \mathrm{~g}$. The shapes of most orbits are elliptical, which means the imbalance of the rotor results in vibrations. The vibrations in the front bearing increase as rotational speed increases, and the maximum amplitude is not more than $3 \mu \mathrm{m}$ under $m 0$ and $m 1$. Thus, waterlubricated hybrid bearings can retrain vibrations and improve stability. The vibration amplitude of $m 1$ is smaller than that of $m 0$ at the same speed. The imbalance of attached mass $m 1$ partially counteracts the vibrations that result from the initial imbalance of the spindle. The maximum vibration amplitude for the orbit of $m 2$ reaches $6 \mu \mathrm{m}$, and the film whirling 


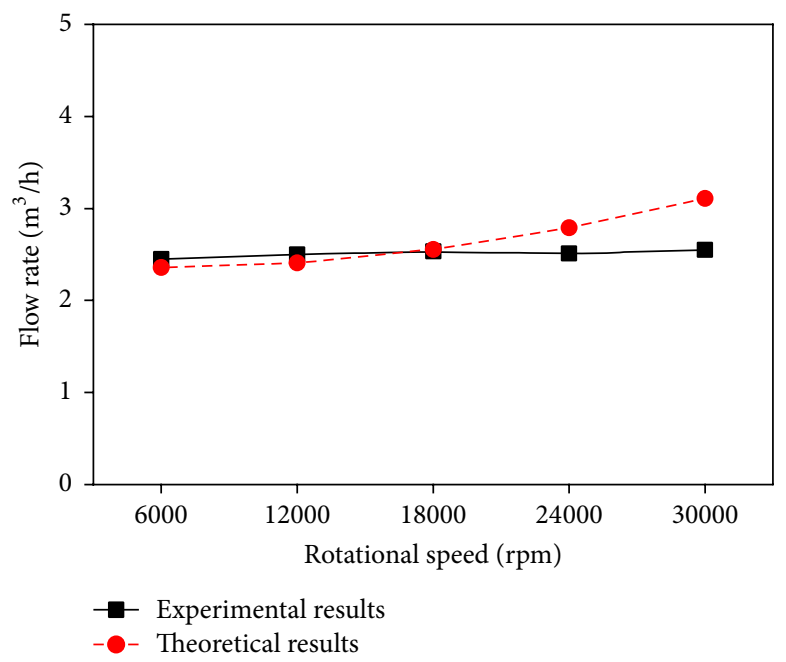

FIGURE 4: Flow rate versus rotational speed at a supply pressure of $2.5 \mathrm{MPa}$.
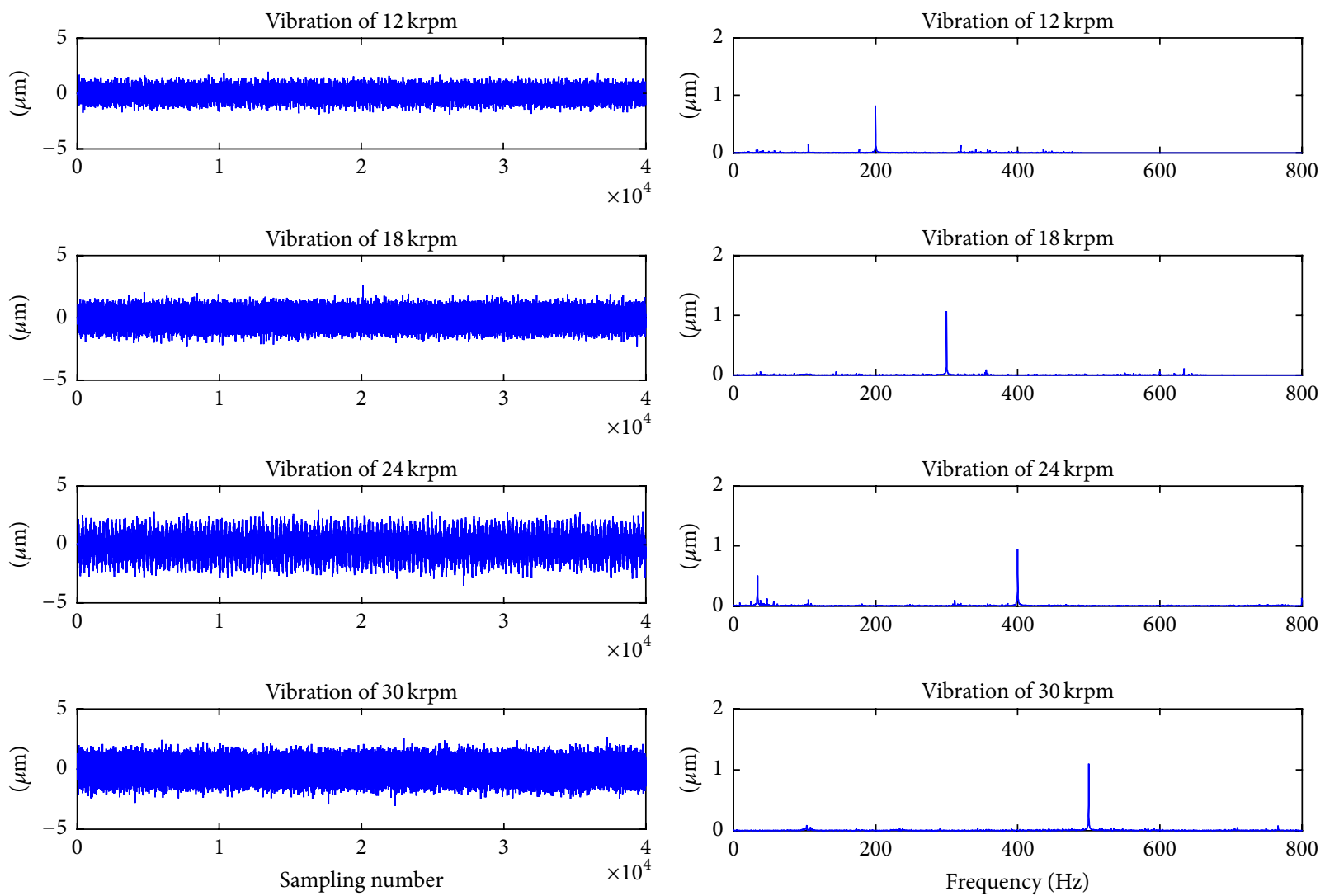

FIGURE 5: Vibration amplitude versus rotational speed in time domain and frequency domain.

appears at 24,000 rpm. The attached mass $m 2$ counteracts and increases the initial imbalance of the spindle. In summary, the hybrid bearings can improve the stability of high-speed spindle systems.

\section{Conclusions}

A new high-speed spindle supported by water-lubricated hybrid journal bearings was developed. Experiments were conducted to study the dynamic performance of the waterlubricated high-speed spindle system. The results indicate that the maximum temperature rise is less than $15^{\circ} \mathrm{C}$ at a speed of 30,000 rpm and a supply pressure of $2.5 \mathrm{MPa}$. The radial run-out of the rotational frequency is approximately $1 \mu \mathrm{m}$. The imbalance excitation method is used to investigate the stability of the spindle system. The orbit is stable up to $24,000 \mathrm{rpm}$ with the initial imbalance of the rotor. Waterlubricated hybrid bearings lowered the temperature rise 


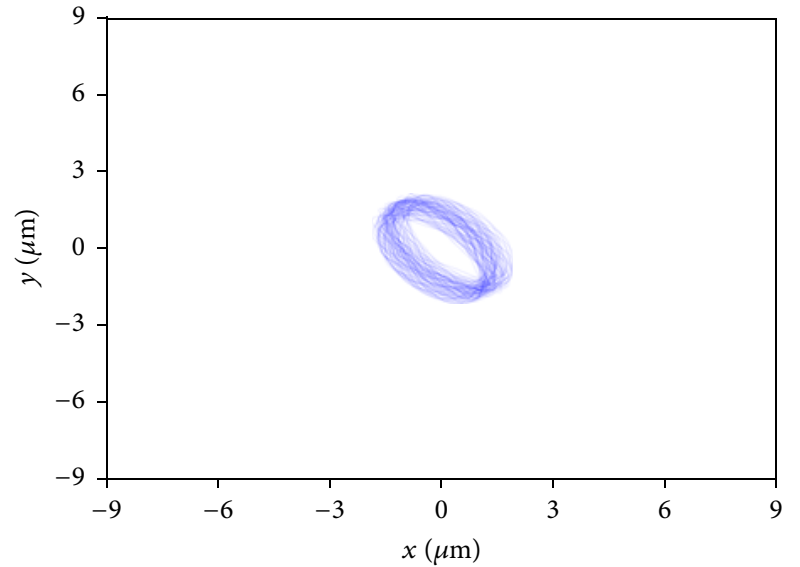

$-m 0,9 \mathrm{krpm}$

(a) $9000 \mathrm{rpm}$

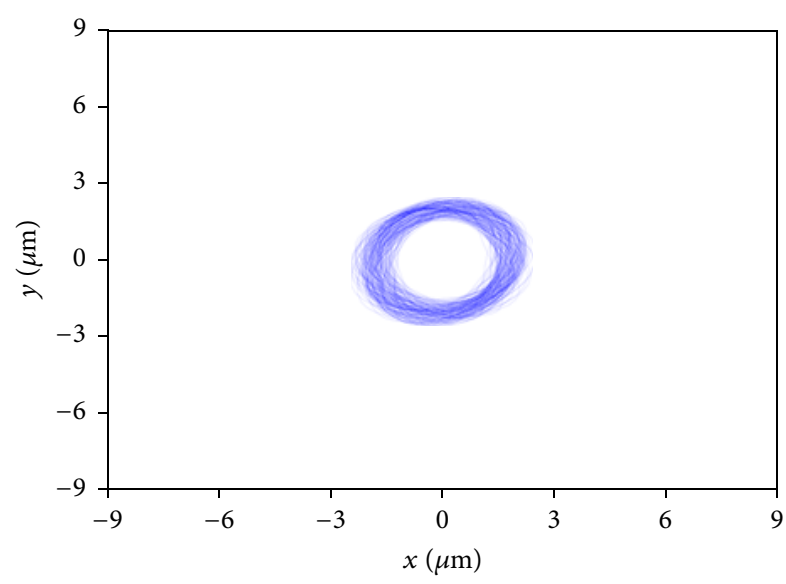

$-m 0,15 \mathrm{krpm}$

(c) $15000 \mathrm{rpm}$

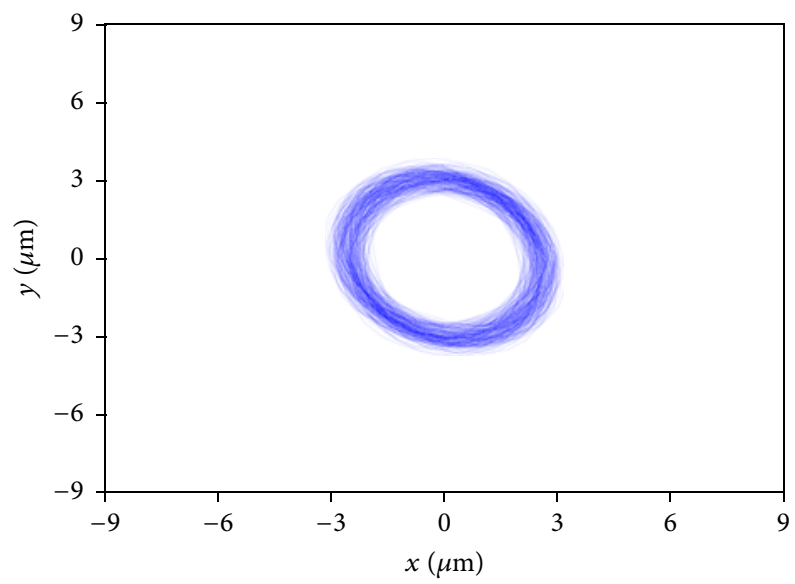

$m 0,21 \mathrm{krpm}$

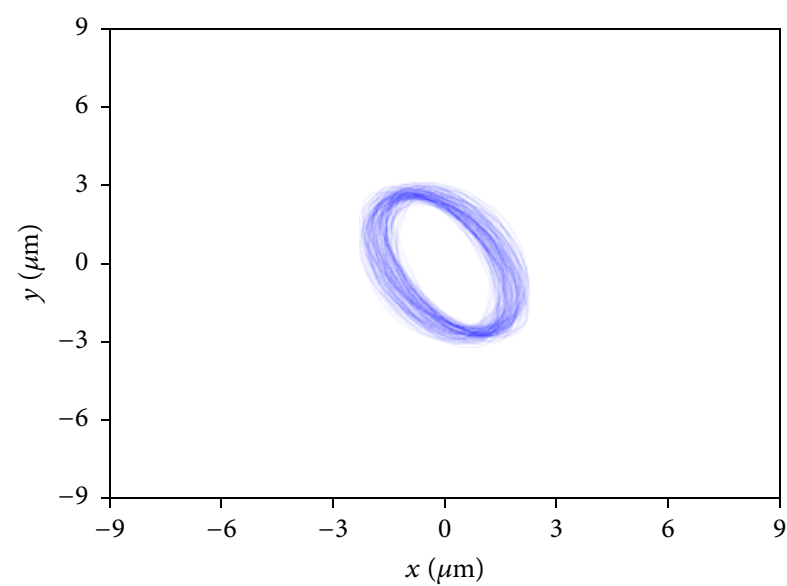

— $m 0,12 \mathrm{krpm}$

(b) $12000 \mathrm{rpm}$

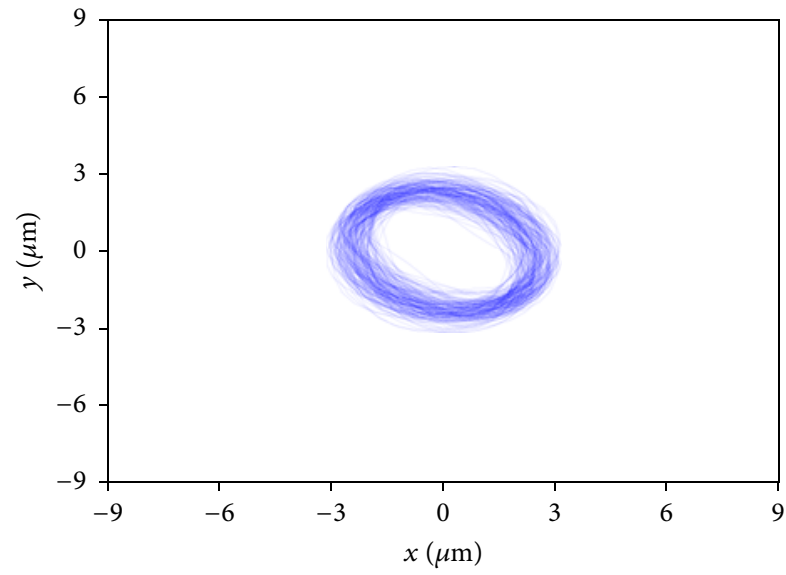

$-m 0,18 \mathrm{krpm}$

(d) $18000 \mathrm{rpm}$

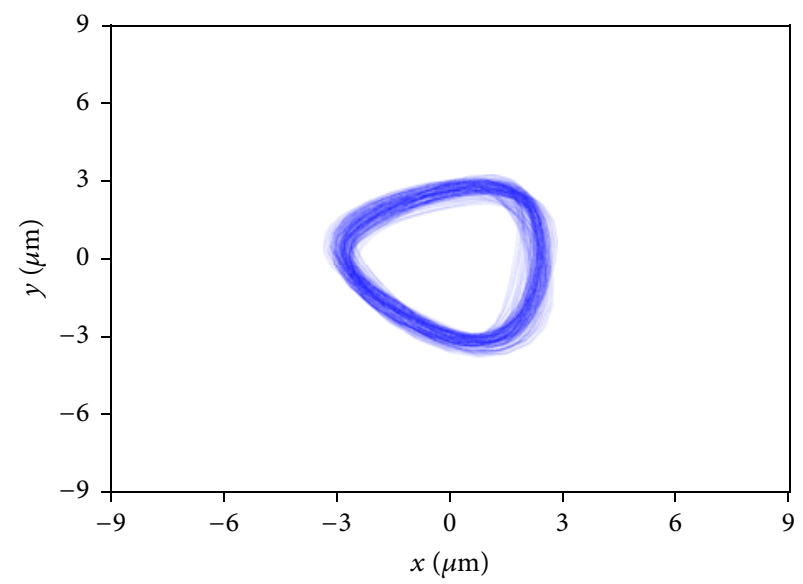

$-m 0,24 \mathrm{krpm}$

(e) $21000 \mathrm{rpm}$

(f) $24000 \mathrm{rpm}$

FIGURE 6: Orbits of the front bearing without attached unbalance mass. 


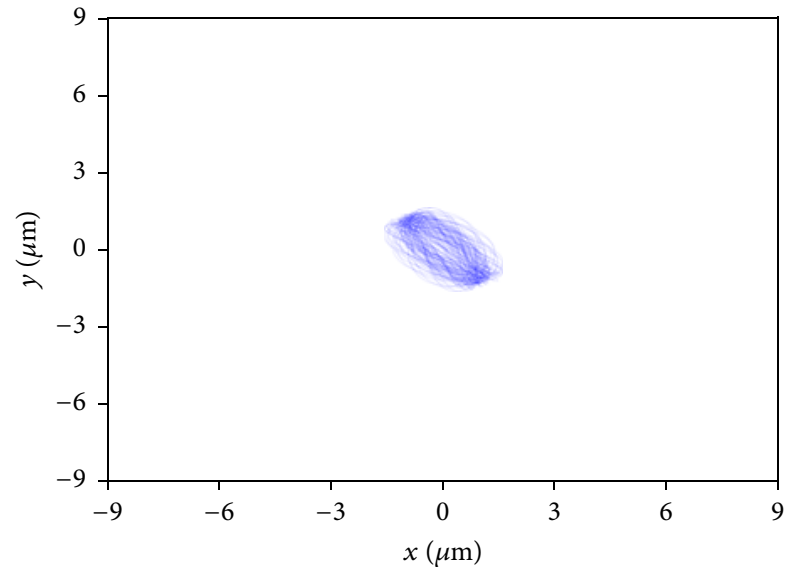

$-m 1,9 \mathrm{krpm}$

(a) $9000 \mathrm{rpm}$

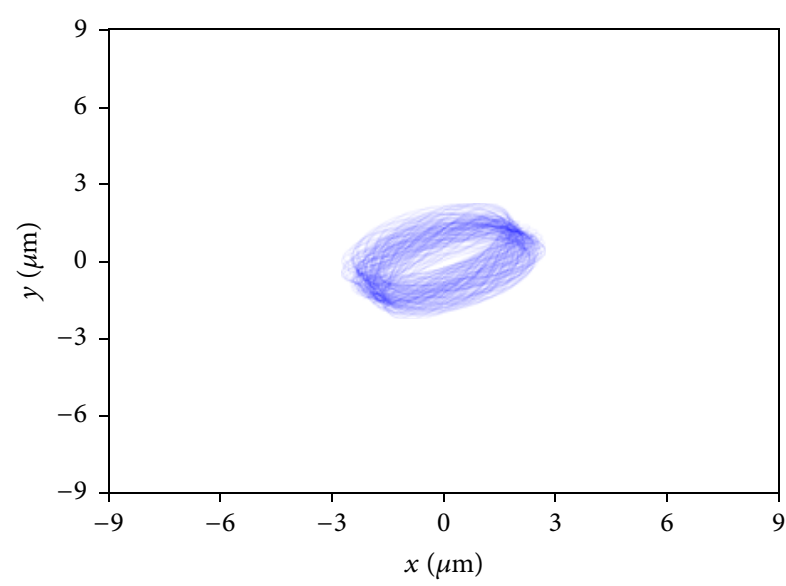

— $m 1,15 \mathrm{krpm}$

(c) $15000 \mathrm{rpm}$

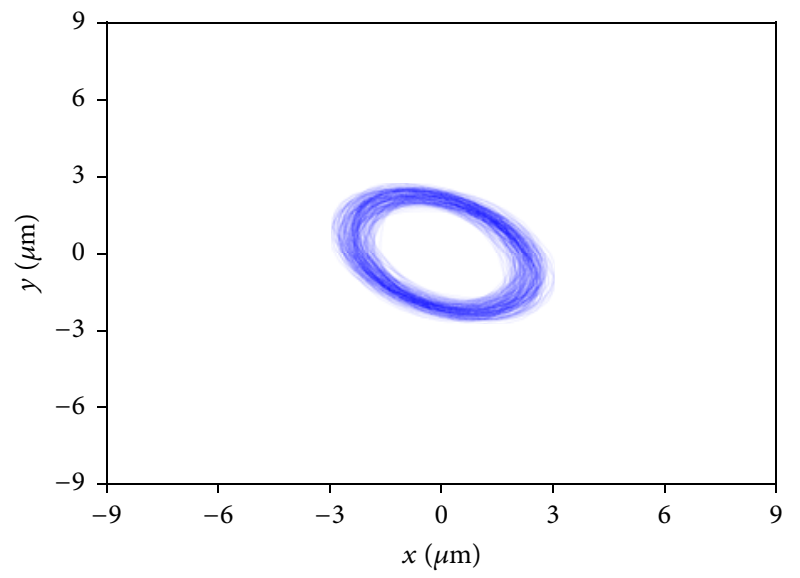

$-m 1,21 \mathrm{krpm}$

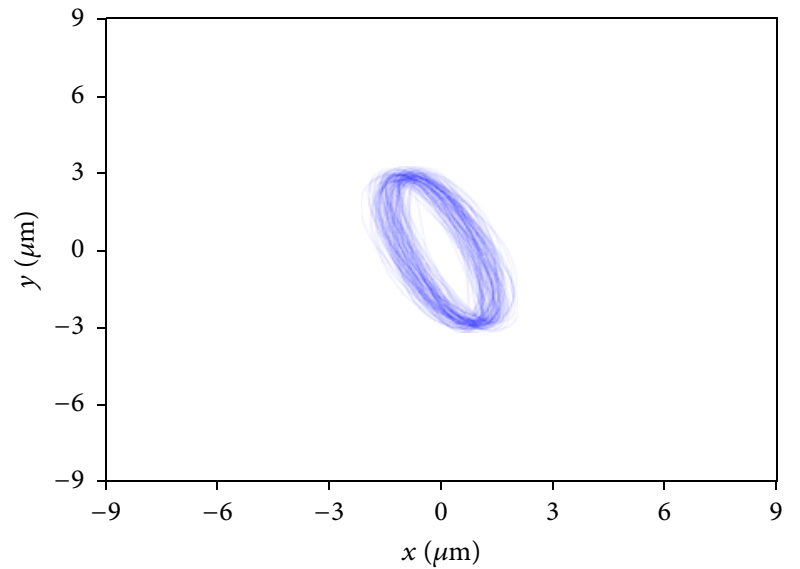

$-m 1,12 \mathrm{krpm}$

(b) $12000 \mathrm{rpm}$

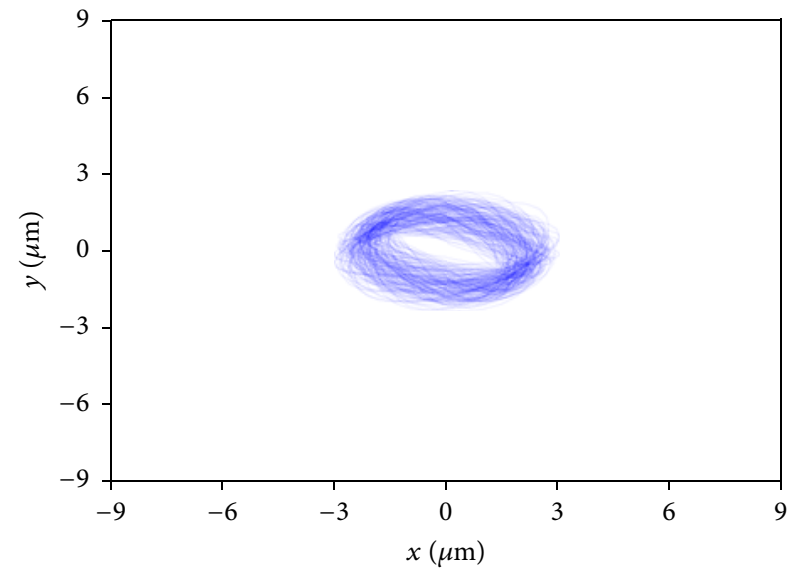

- $m 1,18 \mathrm{krpm}$

(d) $18000 \mathrm{rpm}$

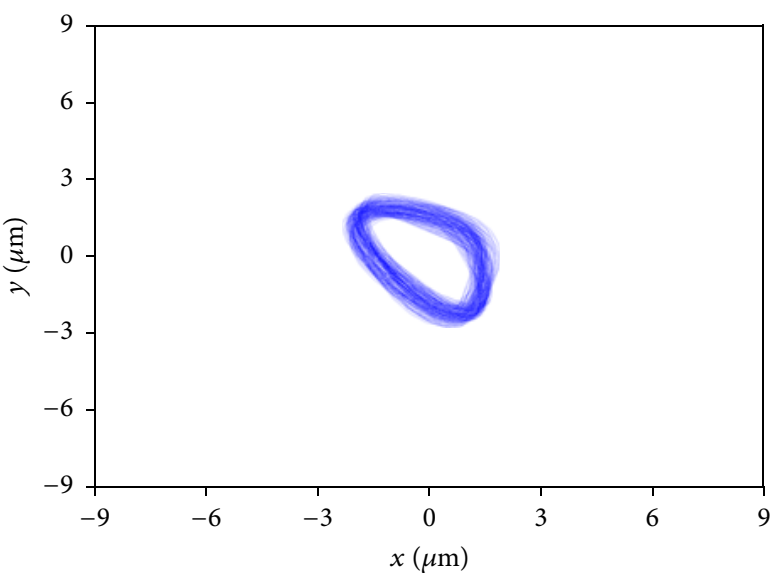

$m 1,24 \mathrm{krpm}$

(f) $24000 \mathrm{rpm}$

(e) $21000 \mathrm{rpm}$

FIGURE 7: Orbits of the front bearing with an attached unbalance mass $m 1=1.7 \mathrm{~g}$. 


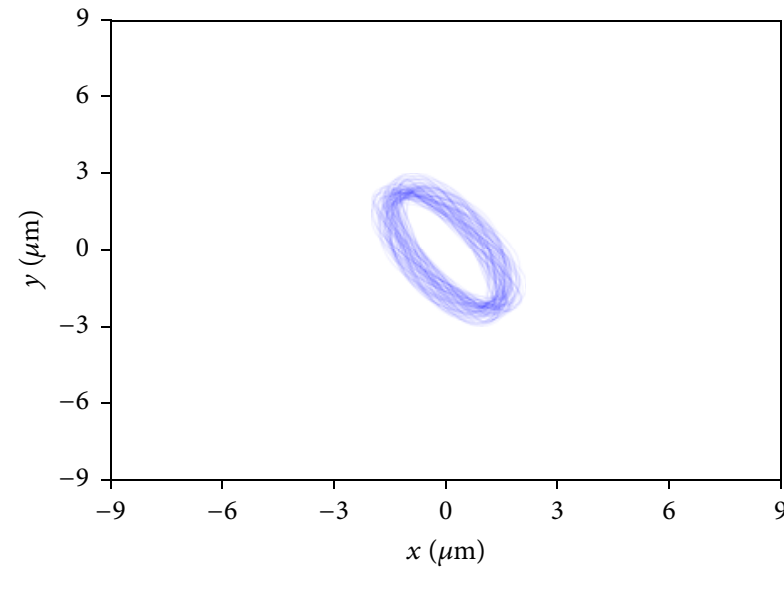

— $m 2,9 \mathrm{krpm}$

(a) $9000 \mathrm{rpm}$

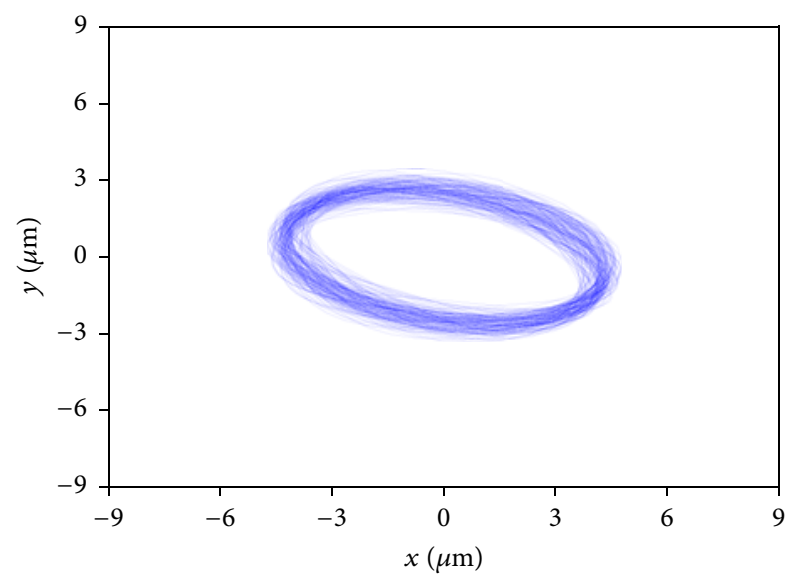

$m 2,15 \mathrm{krpm}$

(c) $15000 \mathrm{rpm}$

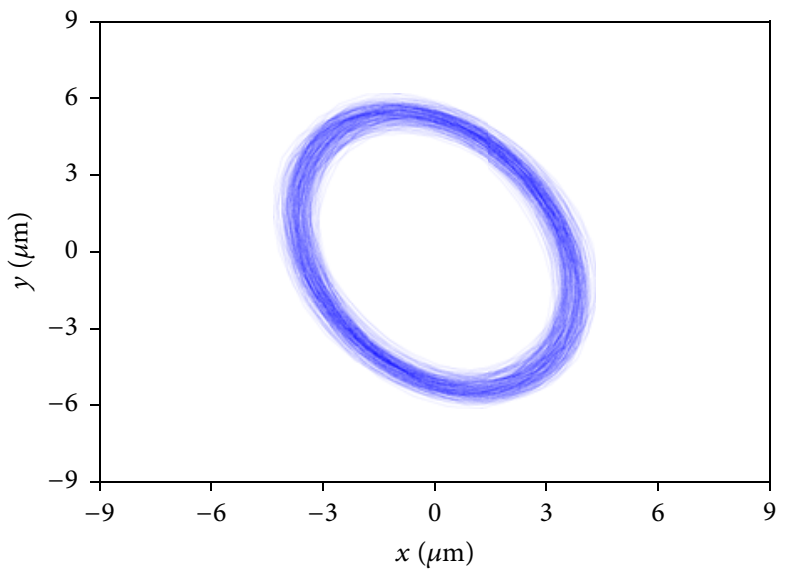

- $m 2,21 \mathrm{krpm}$

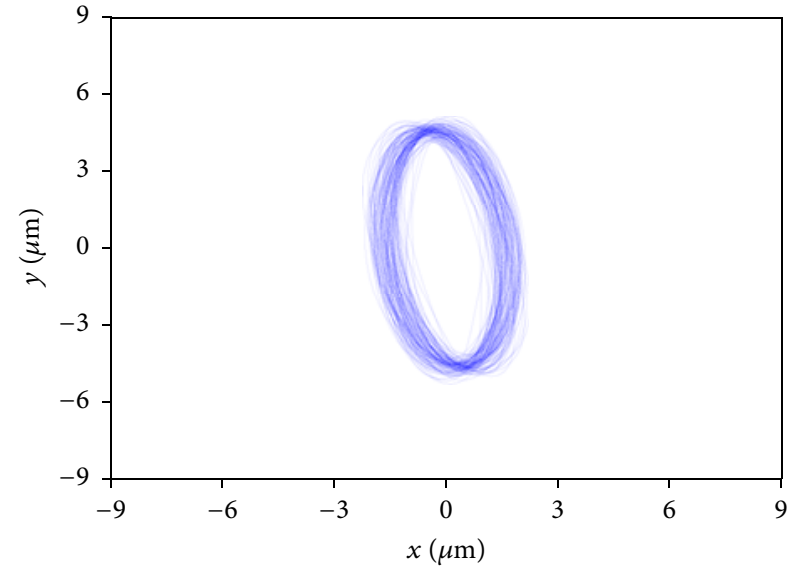

— $m 2,12 \mathrm{krpm}$

(b) $12000 \mathrm{rpm}$

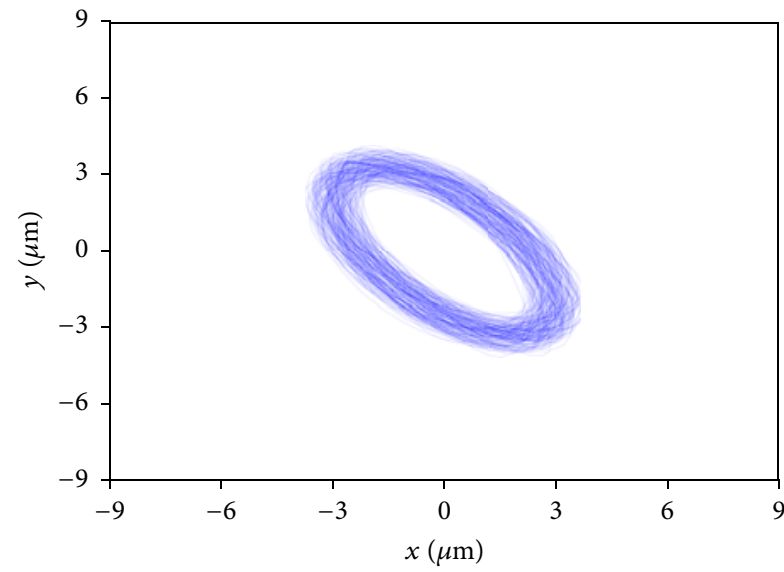

$-m 2,18 \mathrm{krpm}$

(d) $18000 \mathrm{rpm}$

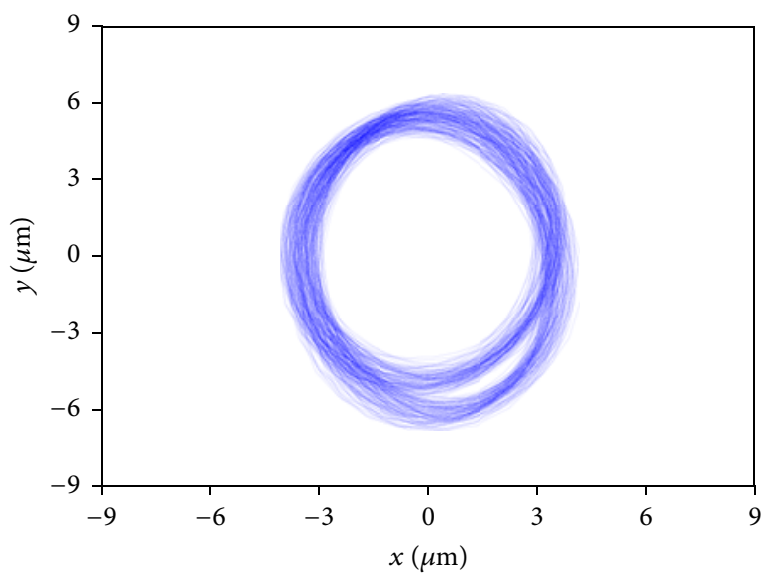

- $m 2,24 \mathrm{krpm}$

(f) $24000 \mathrm{rpm}$

FIgURE 8: Orbits of the front bearing with an attached unbalance mass $m 2=3.0 \mathrm{~g}$. 
and improved the spindle stability. Thus, water-lubricated hybrid journal bearings can replace ceramic bearings and air bearings as support for spindles under high-speed, high-precision, and heavy-load machining conditions. This research may be a useful guide for designing high-speed spindles.

\section{Conflict of Interests}

The authors declare that there is no conflict of interests regarding the publication of this paper.

\section{Acknowledgments}

The work included in this paper was supported by the National Natural Science Fund of China (no. 51505384 and no. 51575421) and the Fundamental Research Funds for the Central Universities (no. 3102015JCS05007).

\section{References}

[1] E. Abele, Y. Altintas, and C. Brecher, "Machine tool spindle units," CIRP Annals-Manufacturing Technology, vol. 59, no. 2, pp. 781-802, 2010.

[2] W. B. Rowe, Hydrostatic, Aerostatic and Hybrid Bearing Design, Butterworth-Heinemann, Oxford, UK, 2012.

[3] S. C. Sharma, V. Kumar, S. C. Jain, R. Sinhasan, and M. Subramanian, "Study of slot-entry hydrostatic/hybrid journal bearing using the finite element method," Tribology International, vol. 32, no. 4, pp. 185-196, 1999.

[4] S. Nakano, T. Kishibe, T. Inoue, and H. Shiraiwa, "An advanced microturbine system with water-lubricated bearings," International Journal of Rotating Machinery, vol. 2009, Article ID 718107, 12 pages, 2009.

[5] K. A. Kurtin, D. Childs, L. San Andres, and K. Hale, "Experimental versus theoretical characteristics of a high-speed hybrid (combination hydrostatic and hydrodynamic) bearing," Journal of Tribology, vol. 115, no. 1, pp. 160-169, 1993.

[6] S. Yoshimoto, T. Kume, and T. Shitara, "Axial load capacity of water-lubricated hydrostatic conical bearings with spiral grooves for high speed spindles: comparison between rigid and complaint surface bearings," Tribology International, vol. 31, no. 6, pp. 331-338, 1998.

[7] S. Yoshimoto, S. Oshima, S. Danbara, and T. Shitara, "Stability of water-lubricated, hydrostatic, conical bearings with spiral grooves for high-speed spindles," Journal of Tribology, vol. 124, no. 2, pp. 398-405, 2002.

[8] B. Bossmanns and J. F. Tu, "A thermal model for high speed motorized spindles," International Journal of Machine Tools and Manufacture, vol. 39, no. 9, pp. 1345-1366, 1999.

[9] L. Wang, S. Pei, X. Xiong, and H. Xu, "Study on the static performance and stability of a water-lubricated hybrid bearing with circumferential grooves and stepped recesses considering the influence of recess sizes," Tribology Transactions, vol. 57, no. 1, pp. 36-45, 2014.

[10] L. Wang, S. Pei, X. Xiong, and H. Xu, "Investigation of the combined influence of turbulence and thermal effects on the performance of water-lubricated hybrid bearings with circumferential grooves and stepped recesses," Proceedings of the Institution of Mechanical Engineers. Part J: Journal of Engineering Tribology, vol. 228, no. 1, pp. 53-68, 2014. 


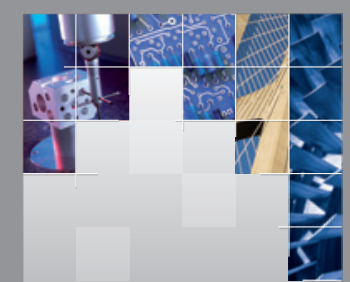

\section{Enfincering}
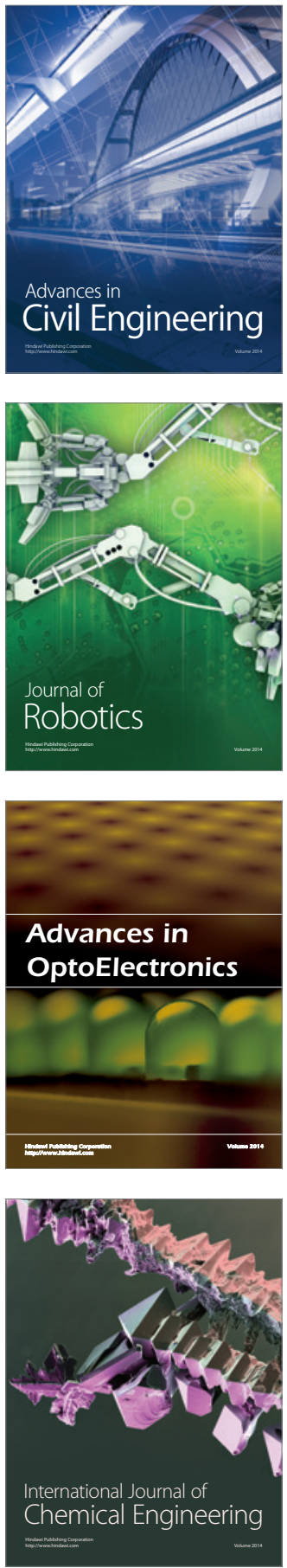

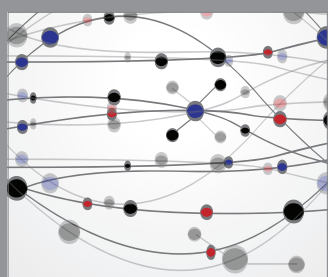

The Scientific World Journal

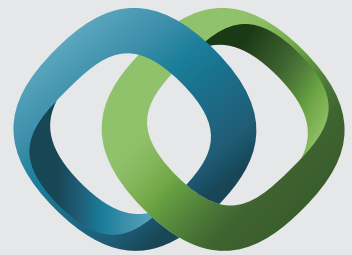

\section{Hindawi}

Submit your manuscripts at

http://www.hindawi.com
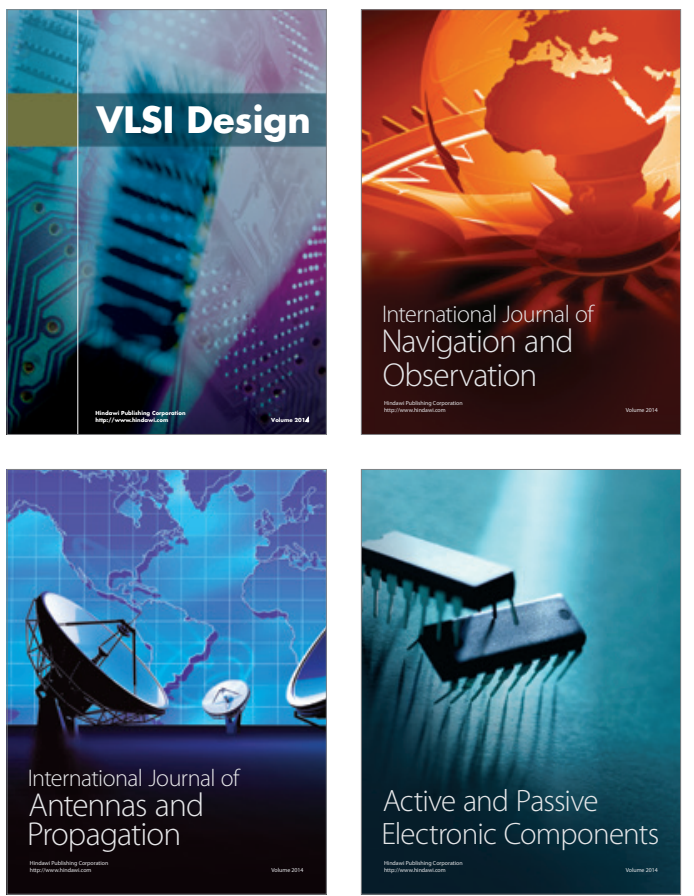
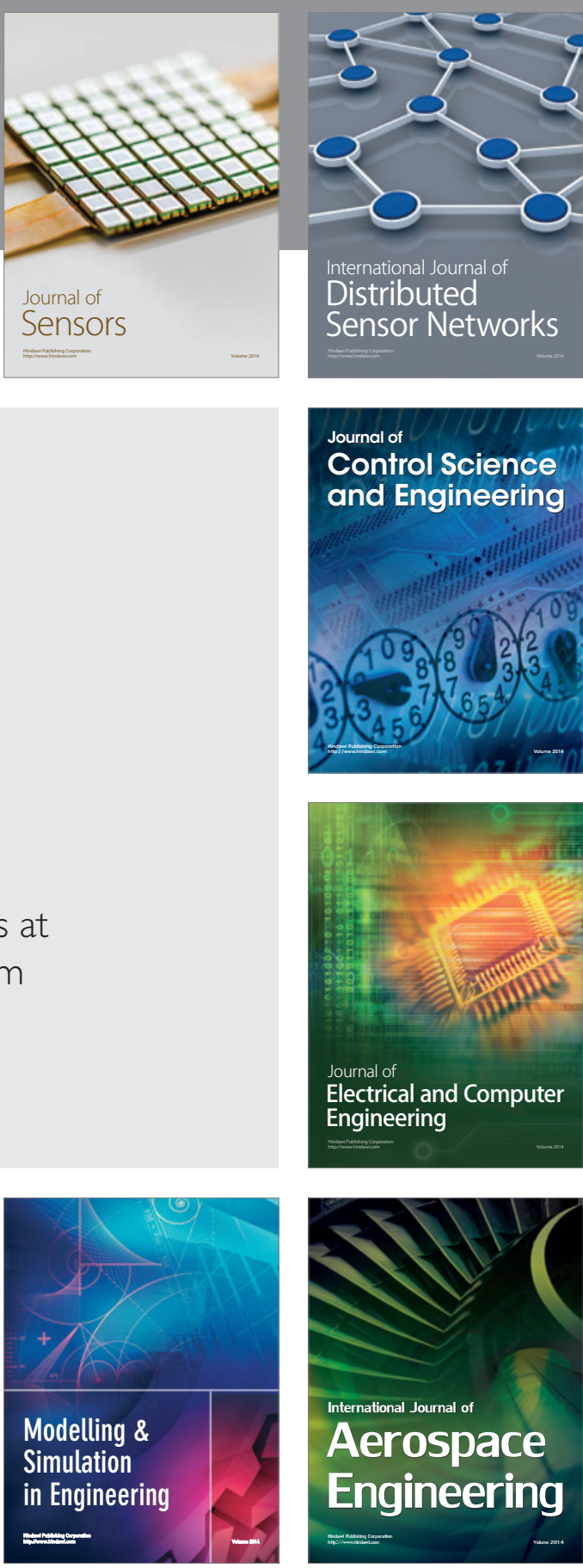

International Journal of

Distributed

Sensor Networks

Journal of

Control Science

and Engineering
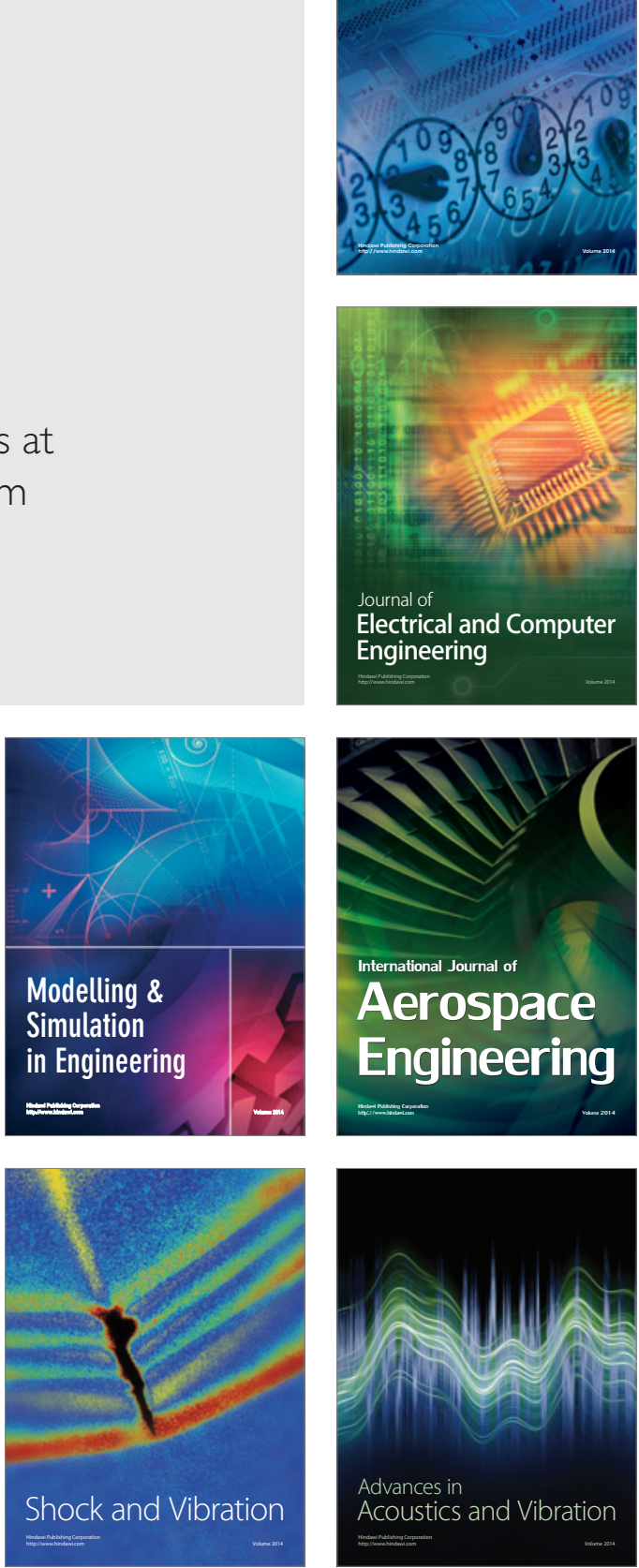